\title{
Complexities in consultations in case of euthanasia or physician-assisted suicide: a survey among SCEN physicians
}

Tessa D. Bergman ${ }^{*}$, H. Roeline W. Pasman and Bregje D. Onwuteaka-Philipsen

\begin{abstract}
Background: In the Netherlands, euthanasia or physician-assisted suicide (EAS) is allowed if due care criteria are met. One criterion is consultation of a second independent physician, often SCEN physicians. The public debate about EAS focuses on patients with psychiatric disorders, dementia, and tired of living, as complex cases. What complexities SCEN physicians perceive during consultation is unknown. This study aims to assess the frequency of EAS consultations that are perceived difficult by SCEN physicians, to explore what complexities are perceived by SCEN physicians during consultation, and to assess what characteristics are associated with difficult consultations.

Methods: Data from 2015 to 2017 from an annual cross-sectional survey among SCEN physicians was used. In 2015, the survey focused on the most difficult consultation that year and in 2016/2017 on the most recent consultation. Frequencies of coded answers to an open-ended question were done to explore what complexities SCEN physicians perceived during their most difficult consultation. Univariable and multivariable logistic regression analyses were used to assess what characteristics were associated with difficult consultations.

Results: $21.6 \%$ of cases consulted by SCEN physicians is perceived difficult. Complexities that SCEN physicians perceive were mainly in contact with patients (79.7\%) and in the assessment of due care criteria (41.0\%). Characteristics that were associated with a higher likelihood of a consultation being difficult are the attending physician being less certain to perform the EAS, patients staying in the hospital, main diagnosis heart failure/CVA, and accumulation of age-related health problems/psychiatry/dementia, and the presence of a psychiatric disorder, or psychosocial or existential problems besides the main diagnosis. Characteristics that were associated with a lower likelihood of a consultation being difficult are high patient's age and physical suffering as reason to request EAS.
\end{abstract}

Conclusion: Complexities perceived by SCEN physicians in EAS consultations are not limited to the 'complex' cases present in the current public debate about EAS, e.g. patients with psychiatric disorders, dementia, and tired of living. Attention for these complexities in intervision could indicate if there is a need among SCEN physicians to enhance knowledge and skills in training and to receive specific support in intervision on these complexities.

Keywords: Euthanasia, Assisted suicide, SCEN physician, Euthanasia consultation, Euthanasia law

\footnotetext{
*Correspondence: bergman.td@gmail.com; eol@amsterdamumc.nl

Department of Public and Occupational Health, Amsterdam Public Health

Research Institute, Amsterdam UMC, Vrije Universiteit Amsterdam, P.O. Box

7057, 1007, MB, Amsterdam, The Netherlands
}

(c) The Author(s). 2020 Open Access This article is distributed under the terms of the Creative Commons Attribution 4.0 International License (http://creativecommons.org/licenses/by/4.0/), which permits unrestricted use, distribution, and reproduction in any medium, provided you give appropriate credit to the original author(s) and the source, provide a link to the Creative Commons license, and indicate if changes were made. The Creative Commons Public Domain Dedication waiver (http://creativecommons.org/publicdomain/zero/1.0/) applies to the data made available in this article, unless otherwise stated. 


\section{Background}

In $2015,4.6 \%$ of deaths in the Netherlands was due to euthanasia or physician-assisted suicide (EAS) [1]. EAS is regulated under the Dutch Euthanasia Act (2002): a physician will not be prosecuted for performing EAS if the due care criteria are met and he/she reports the EAS to the Regional Euthanasia Review Committee [2]. The due care criteria are (a) the patient's request is voluntary and well-considered; (b) the patient's suffering is unbearable and without prospect of relief; (c) the patient is informed about his/her situation and prospects; (d) there is no reasonable alternative solution; (e) another independent physician has consulted the patient; (f) the physician terminated the patient's life with due medical care and attention [2]. The second independent physician assesses whether the due care criteria (a t/m d) are met and advices the attending physician $[3,4]$. In $78 \%$ of the consultations a SCEN physician (Support and Consultation on Euthanasia in the Netherlands) is consulted as second independent physician [1]. The SCEN project is a programme of the Royal Dutch Medical Association (RDMA) with the aim to improve the quality of consultation and thereby the quality of EAS [3]. SCEN physicians receive a 3-day training programme in which their tasks and the Dutch Euthanasia Act are discussed [5]. When active as SCEN physician, they are expected to attend intervision three times per year in their SCENregion. Both training and intervision are considered important to maintain quality of consultation [5].

In recent years, the public debate about EAS has focused on patients with psychiatric disorders, dementia, and older people tired of living as complex cases [6-8]. Nonetheless, these patients can meet the due care criteria. For patients tired of living, an important topic is whether these patients have medically classifiable diseases, which is a requirement to meet the due care criteria. These are currently frequently operationalized as accumulation of age-related health problems in the tired of living debate. In 2016, $4 \%$ of the requests was underlain by a psychiatric disorder, $3 \%$ by dementia and $6 \%$ by no serious physical or psychiatric illness [1]. According to a study among attending physicians, significantly less physicians found EAS conceivable for patients with a psychiatric disease, dementia or those being tired of living compared to patients with cancer or other physical diseases [7].

Yet, these complex cases present in the public debate might not cover all complexities that can arise in EAS practice. Research has been conducted among attending physicians, but SCEN physicians differ from attending physicians with regard to three aspects. First, they are specifically trained in assessing the due care criteria and have the most experience. Therefore, they are the best to provide information on complexities. Second, they have a different relationship with the patient. Whereas an attending physician has a long-term relationship with the patient, the SCEN physician often consults the patient once to assess the due care criteria. Third, they fulfil another role in the process of EAS compared to the attending physician. They assess the criteria based on the law, and thus, unlike attending physicians, they do not have to take their personal boundaries into consideration. It stands to reason that SCEN physicians also experience complexities, although those may be different from the attending physicians. However, what complexities SCEN physicians perceive during EAS consultations, is unknown until now. Therefore, the following research questions will be addressed: What is the frequency of consultations that are perceived difficult by SCEN physicians? What complexities do SCEN physicians perceive during consultation? What characteristics are associated with SCEN physicians perceiving a consultation as difficult?

\section{Methods \\ Study design and data collection}

From 2008 onwards, an annual survey of RDMA is held among SCEN physicians in the Netherlands to collect specific data on their most recent consultation. Data from 2015, 2016 and 2017 was included in this crosssectional study. The response rate was $78.7 \%(N=546)$ in $2015,76.4 \%(N=542)$ in 2016 and $72.1 \%(N=498)$ in 2017. Only questionnaires with complete data for the dependent variables were analysed. This resulted in analysis of 498 questionnaires filled in by 498 SCEN physicians for 2015 and, in total, 938 questionnaires filled in by 573 SCEN physicians for 2016 and 2017. In 2015, the questionnaire focused on the most difficult consultation instead of the most recent consultation. The data from 2015 were used to explore what characteristics of complex consultations are according to SCEN physicians. The data from 2016 and 2017, about the most recent consultation, were used to assess the frequency of consultations perceived difficult by SCEN physicians and what characteristics are associated with consultations that are perceived difficult by SCEN physicians. As the 2015 data only included difficult consultations, these data could not be included in these analyses of difficult versus non difficult consultations.

\section{Questionnaires}

Questionnaires were developed for the purpose of monitoring SCEN and were used in a previous study of Brinkman-Stoppelenburg et al. (2014) [9]. Both the questionnaire in 2015 and the questionnaires in 2016 and 2017 included questions about the amount of consultations in the last year, the setting in which they were provided, and patient characteristics. Specific questions 
were posed about the most difficult (2015) or most recent $(2016 / 2017)$ consultation the SCEN physician conducted. In the questionnaire in 2015 an open-ended question was included on what complexities SCEN physicians had perceived. This open-ended question consisted of five prescribed categories for which the SCEN physicians could indicate what they considered complex (if anything in that category) to ensure that respondents answered extensively. The five prescribed categories were patient characteristics, assessment of due care criteria, patient's relatives, health professionals and other. Based on these categories, questions were formulated for the questionnaire in 2016 and 2017 on perceived difficulty of consultation, for four aspects: the assessment of the due care criteria, patient characteristics, patient's relatives, and health professionals. The questions had a 5pointscale $(1=$ not difficult at all, $5=$ extremely difficult $)$ and if they scored 4 or 5 for at least one of the aspects, the consultation was considered as difficult (dichotomous). Hereafter, we will refer to consultations being perceived as difficult by SCEN physicians, as difficult consultations.

\section{Analysis}

Statistical analyses were performed using SPSS IBM 22. Descriptive statistics were used to describe the frequency of characteristics of (difficult) consultations for the most difficult (2015) and most recent consultations (2016/ 2017) separately. Characteristics of the 2015 sample and the 2016/2017 sample are presented combined in Table 1 for each year separately.

To assess what complexities SCEN physicians perceived during their most difficult consultation (2015), the answers to the open-ended question on perceived complexities were coded by BDOP and HRWP separately and then compared. Frequency analysis of the codes was done to assess how often specific complexities were encountered.

To assess what characteristics are associated with difficult consultations $(2016 / 2017)$ we included 24 independent variables from three categories. First, patient characteristics were age, sex, residency, main diagnosis, other diagnoses besides the main diagnosis (5 variables), and important reasons to request EAS (11 variables). Second, characteristics of the attending physician included the profession, works at End of Life clinic, and certainty of the attending physician to perform EAS (hereafter certainty attending physician). Third, we included the number of consultations per year as characteristic of SCEN physicians. Several univariable logistic regression analyses and a multivariable logistic regression analysis with difficult consultations as the dependent variable were conducted to assess what characteristics were significantly associated. Characteristics were included in analyses if they counted at least 5 people in each group. Both linearity and multicollinearity were checked. All characteristics that were statistically significant $(p<0.05)$ in univariable logistic regression analyses were included in the multivariable logistic regression analysis. These analyses were repeated for the separate aspects with a prevalence of complexity of at least $10 \%$, namely patient characteristics and assessment of the due care criteria, to assess if there were any differences between these aspects. No analyses were conducted for the aspects interaction with the patient's relatives and health professionals because the numbers of cases in which these were considered difficult were very low and analyses would therefore not give a precise estimate of the effect due to low power. Sensitivity analysis, with the use of generalised estimating equations (GEE), were used to check for possible clustering within SCEN physicians.

\section{Results \\ Frequency of difficult consultations and characteristics of patients of whom SCEN physicians judged their request for EAS}

The sample of 2016 and 2017 consisted of patients of the most recent consultation of the SCEN physician. In 2016 and 2017, 21.6\% of consultations were perceived difficult by SCEN physicians: 203 out of 938 consultations. The assessment of due care criteria was most often perceived as difficult (14.8\%), followed by patient characteristics (10.3\%). Difficult consultations due to interaction with the patient's relatives and health professionals were less prevalent, namely 4.4 and $3.1 \%$. Cancer was the most prevalent main diagnosis and makes up for $75 \%$ of the not difficult cases, while for the most difficult (from 2015) and difficult cases (from 2016/2017) this was significantly lower, namely 34 and 36\%. In 2016 and 2017, 29 cases (14\%) concerning patients diagnosed with accumulation of age-related health problems were considered difficult and 28 (4\%) as not difficult. The diagnoses accumulation of age-related health problems, dementia and psychiatric disorder were significantly less prevalent in not difficult cases compared to (most) difficult consultations (Table 1).

\section{Perceived complexities by SCEN physicians during the most difficult consultation}

SCEN physicians described what complexities they perceived during their most difficult consultation in an open-ended question included in 2015. Table 2 consists of the results after coding the answers to the open-ended question which was filled in by 449 of the 498 SCEN physicians. These complexities concerned five aspects. First, patient characteristics was 
Table 1 Characteristics of patients with EAS request assessed by SCEN physicians, by experienced difficulty and year (absolute numbers and rounded percentages)

\begin{tabular}{|c|c|c|c|c|c|c|c|c|c|}
\hline & \multirow{2}{*}{\multicolumn{3}{|c|}{$\begin{array}{l}2015 \text { Most difficult } \\
\text { consultation }(N=498)\end{array}$}} & \multicolumn{6}{|c|}{ 2016/2017 Most recent consultation } \\
\hline & & & & \multicolumn{3}{|c|}{ Difficult $(N=203)$} & \multicolumn{3}{|c|}{ Not difficult $(N=735)$} \\
\hline & $\mathrm{N}$ & $\%$ & $(95 \% \mathrm{Cl})$ & $\mathrm{N}$ & $\%$ & $(95 \% \mathrm{Cl})$ & $\mathrm{N}$ & $\%$ & $(95 \% \mathrm{Cl})$ \\
\hline \multicolumn{10}{|l|}{ Age } \\
\hline$<70$ years & 208 & 45 & $(40-49)$ & 78 & 39 & $(32-46)$ & 260 & 36 & $(32-39)$ \\
\hline 70-79 years & 101 & 22 & $(18-26)$ & 36 & 18 & $(13-24)$ & 240 & 33 & $(30-36)$ \\
\hline$\geq 80$ years & 157 & 34 & (30-38) & 86 & 43 & $(36-50)$ & 229 & 31 & $(28-35)$ \\
\hline Sex (female) & 255 & 53 & $(48-57)$ & 104 & 52 & $(44-58)$ & 339 & 46 & $(43-50)$ \\
\hline \multicolumn{10}{|l|}{ Main diagnosis } \\
\hline Cancer & 162 & 34 & $(29-38)$ & 73 & 36 & $(30-43)$ & 551 & 75 & $(72-78)$ \\
\hline Heart failure/CVA & 42 & 9 & $(6-11)$ & 23 & 11 & $(8-16)$ & 35 & 5 & $(3-6)$ \\
\hline MS/ALS & 21 & 4 & $(3-6)$ & 7 & 4 & $(2-7)$ & 22 & 3 & $(2-4)$ \\
\hline COPD & 17 & 4 & $(2-5)$ & 7 & 4 & $(2-7)$ & 33 & 5 & $(3-6)$ \\
\hline Accumulation of age-related health problems & 53 & 11 & $(8-14)$ & 29 & 14 & $(10-20)$ & 28 & 4 & $(3-5)$ \\
\hline Dementia & 44 & 9 & $(7-12)$ & 17 & 8 & $(5-13)$ & 9 & 1 & $(1-2)$ \\
\hline Psychiatric disorder & 46 & 10 & $(7-12)$ & 18 & 9 & $(6-13)$ & 3 & 0 & $(0-1)$ \\
\hline Other & 99 & 21 & $(17-24)$ & 28 & 14 & (10-19) & 53 & 7 & $(6-9)$ \\
\hline
\end{tabular}

Missing values ranging from 2 to 32

the most prevalent described aspect (79.7\%) and most mentioned complexities were: no short-term lifethreatening disease (18.8\%), difficulties in communication (18.4\%), psychiatric disorders (13.5\%). Second, in $41.0 \%$ of the cases the assessment of due care criteria was perceived difficult and most mentioned complexities included: suffering hard to assess due to the situation of the patient (11.8\%), early consultation (8.9\%), mental competence hard to assess (6.6\%). Third, interaction with the patient's relatives was mentioned as difficult in $26.3 \%$ of the cases and most mentioned perceived complexities were: relatives are not ready for/have problems with the EAS (7.5\%), relatives exert pressure on the physician (5.6\%), problems within the family that are not directly related to the EAS request (4.6\%). Fourth, in $23.4 \%$ of the cases interaction with the health professionals was perceived as difficult. These mainly concerned problems with the attending physician: pressure/not understanding doubts or decision SCEN physician (8.9\%), doubting/unclear/unprepared attending physician (6.1\%), attending physician does not want to perform the EAS (2.4\%). Fifth, in $13.4 \%$ of the cases the perceived complexities concerned other aspects. Examples are that an earlier SCEN physician judged differently (2.9\%) and little experience of SCEN physician with disease (2.6\%). Table 3 gives examples of quotes about perceived difficulties.

\section{Characteristics associated with difficult consultations as perceived by SCEN physicians}

Table 4 presents descriptive statistics, univariable ORs and multivariable ORs of each characteristic of the most recent consultation in 2016 and 2017. Six characteristics remained statistically significant in multivariable analysis as associations with difficult consultations. Compared to attending physicians who already promised to grant the request, attending physicians who had doubts about or did not want to grant the request had 4.48 higher odds of difficult consultations. Consultations concerning patients between 70 and 79 years old $(\mathrm{OR}=0.38)$ and older than 80 years $(\mathrm{OR}=0.53)$ had a lower likelihood of difficult consultations, compared to patients younger than 70 years. Compared to patients staying at home, patients staying at the hospital had 3.01 higher odds of difficult consultations. Compared to cancer patients, patients with health failure or cerebrovascular accident $(\mathrm{CVA})(\mathrm{OR}=4.43)$, patients with accumulation of age-related health problems, dementia or psychiatric disorder $(\mathrm{OR}=6.94)$ or other diagnoses $(\mathrm{OR}=3.42)$, such as Parkinson's disease $(N=13)$ and lung fibrosis $(N=6)$, had higher odds of difficult consultations. Besides the main diagnosis, the presence of a psychiatric disorder $(\mathrm{OR}=3.91)$ or psychosocial or existential problems $(\mathrm{OR}=2.25)$ had higher odds of difficult consultations. Physical suffering as an important reason for the EAS request had a lower 
Table 2 Perceived complexities by SCEN physicians during the most difficult consultation, 2015

Most difficult consultation $N=449 *$ (\%)

Patient characteristics

79.7

No short-term life-threatening disease (e.g. accumulation of age-related health problems, chronic diseases, invalidity)

Communication was difficult (e.g. coma, confused, not clear, aphasic)

Psychiatric problems

Ambivalence towards death wish

Patient was demanding, angry

Dementia, cognitive decline

Patient was young

Psychosocial problems (e.g. tired of living, loneliness)

Time pressure due to medical state

Assessment of the due care criteria

41.0

Suffering hard to assess due to the situation of the patient

An early consultation

Mental competence hard to assess

Unbearable suffering hard to imagine

Treatment options hard to define

Suffering hard to asses due to lack of information (from patient/file/physician)

Hard to assess whether the request was voluntary

Patient's relatives

Relatives aren't ready for/have problems with the EAS

Relatives exert pressure on the physician

Problems within the family (not related to the EAS e.g. grief, no contact with children, family lives far away)

Patient wants EAS together with partner

Family cannot handle the care for the patient

Patient provides care for children/partner

Pressure from relatives on patient

Health professionals

Pressure/not understanding doubts or judgement of the SCEN physician

Doubting/unclear/unprepared attending physician

Attending physician does not want to perform the EAS

Attending physician was influenced by the patient and relatives

Suboptimal care (e.g. too little care, not in place wished for, futile treatment)

Attending physician already promised to perform the EAS

Bad contact between attending physician and patient

(Part of) health professionals are against EAS/agitation among health professionals

Attending physician expected more counseling from the SCEN physician

An earlier SCEN physician judged differently 
Table 2 Perceived complexities by SCEN physicians during the most difficult consultation, 2015 (Continued)

\begin{tabular}{ll}
\hline Most difficult consultation $N=449^{*}(\%)$ & 0.6 \\
\hline Questionable whether the second physician was independent & 0.6 \\
Consultation with other SCEN physician necessary & 1.5 \\
Other
\end{tabular}

*More than 1 answer possible; 449 of 498 SCEN physicians answered this question

odds of difficult consultations $(\mathrm{OR}=0.62)$. GEE was conducted as sensitivity analysis. The ORs and CIs of the multivariable logistic regression were comparable to the ORs and CIs in the GEE.

12 out of 13 cases that concerned patients that requested EAS because of depression were difficult cases. However, with only one case for which the consultation was not difficult, depression was not included in analyses.

Table 3 Examples of perceived complexities described by SCEN physicians during the most difficult consultation, 2015

\section{Patient characteristics}

"A vital man; he still walked and cycled"

"A young patient with a medical situation that was hard to describe; the patient was critical towards me and was resistant to have a conversation"

"Patient had reoccurring doubts about the euthanasia; at moments she seemed convinced, but later she had doubts"

\section{Assessment of the due care criteria}

"The patient wanted a judgment if euthanasia was possible beforehand; at the time of consultation, unbearable suffering or a request were not present"

"The patient was adequate in his response capacities, especially in the presence of relatives. However, when I talked to him alone, the characteristics of his dementia became very clear"

"I found the unbearable suffering hard to assess. He said unbearable suffering, but there was still a lot that he enjoyed to do"

\section{Patient's relatives}

"The partner was really sad; his vison was not crystallized; paid a lot of attention to"

"They were angry; the euthanasia was already promised. Due to a gastrointestinal bleeding, the situation was further worsened, but they still demanded the euthanasia"

"Disagreement between the children about their mother's wish"

\section{Health professionals}

"I felt pressured. The attending physician wasn't open for alternative treatment options and advice from $\mathrm{me}^{\prime \prime}$

"The general practitioner was unclear towards me, the patient and himself"

"Really odd consult request. Both the general practitioner and the psychiatrist knew that the patient wouldn't meet the due care criteria. I felt used"

\section{Other aspects}

"No experience with a young man taking such a decision" "I notice resistance in myself with these chronic physical problems combined with personality problems. Is this the purpose of the euthanasia law?"

"For myself heart-breaking. Given the situation, I supported it completely. I experience less resistance with a 90 year old with cancer [case concerning a young woman]"

\section{Characteristics associated with difficult consultations as perceived by SCEN physicians for the assessment of due care criteria and patient characteristics}

For the two aspects that were most frequently considered difficult, namely the assessment of due care criteria and patient characteristics, we performed separate multivariable analyses (Table 5). Four characteristics of consultations remained significantly associated with perceived difficulty of the assessment of due care criteria are. Compared to attending physicians who already promised to grant the request, attending physicians who had doubts about or did not want to grant the request had 4.69 higher odds of difficult assessment of due care criteria. Compared to patients aged younger than 70 years, patients aged between 70 and 79 years $(\mathrm{OR}=0.37)$ and older than 80 years $(\mathrm{OR}=0.41)$ had a lower odds of difficult assessment of due care criteria. Patients with the main diagnoses heart failure or cerebrovascular accident $(\mathrm{CVA})(\mathrm{OR}=3.45)$, accumulation of age-related health problems, dementia or psychiatric disorder $(\mathrm{OR}=$ 13.52) or other diagnoses $(\mathrm{OR}=5.05)$ had a higher odds of difficult assessment of due care criteria, compared to patients with cancer. Patients with psychosocial or existential problems besides their main diagnosis had 2.25 higher odds of difficult assessment of due care criteria, compared to patient without these problems.

Seven characteristics remained significantly associated with characteristics of patients that contribute to a consultation being perceived difficult. Compared to the attending physicians being a general practitioner, the attending physician being a medical specialist had a 3.02 higher odds of characteristics of patients that contribute to a consultation being perceived difficult. Compared to attending physicians who already promised to grant the request, attending physicians who had doubts about or did not want to grant the request had 3.52 higher odds of characteristics of patients that contribute to a consultation being perceived difficult. Patients aged between 70 and 79 years had a lower odds of characteristics of patients that contribute to a consultation being perceived difficult $(\mathrm{OR}=0.41)$, compared to patients younger than 70. Compared to patients staying at home, patients staying in a hospital $(\mathrm{OR}=5.08)$ or hospice $(\mathrm{OR}=3.27)$ had higher odds of characteristics of patients that contribute to a consultation being perceived difficult. Consultations 
Table 4 Characteristics associated with difficult consultations as perceived by SCEN physicians, 2016-2017

\begin{tabular}{llll}
\hline & $\begin{array}{l}\text { Difficult } \\
(N=203)\end{array}$ & $\begin{array}{l}\text { Not difficult } \\
(\mathrm{N}=735)\end{array}$ & $\begin{array}{l}\text { Univariable } \\
\text { Odds ratio } \\
(95 \% \mathrm{Cl})\end{array}$ \\
& $\mathrm{N}(\%)$ & $\mathrm{N}(\%)$ & $\begin{array}{l}\text { Odds ratio } \\
(95 \% \mathrm{Cl})\end{array}$
\end{tabular}

\section{SCEN physician}

Number of consultations per year

$\begin{array}{llll}<5 & 11(5.5) & 52(7.1) & 1 \\ 5-9 & 53(26.5) & 190(25.9) & 1.32(0.64-2.7) \\ 10-14 & 52(26) & 212(28.9) & 1.16(0.57-2.38) \\ \geq 15 & 84(42) & 280(38.1) & 1.42(0.71-2.84)\end{array}$

\section{Attending physician}

Profession

General practitioner

Medical specialist

Elderly care physician

Works at End of life clinic

Certainty of decision before consultation

Already promised to grant the request

Decided to grant the request

Probably wants to grant the request

Doubts about/doesn't want to grant the request

$\begin{array}{llll}151(81.2) & 665(92.7) & 1 & 1 \\ 17(9.1) & 23(3.2) & 3.26(1.7-6.24) & 1.23(0.48-3.17) \\ 18(9.7) & 29(4) & 2.73(1.48-5.05) & 0.73(0.31-1.69) \\ 46(22.8) & 49(6.7) & 4.13(2.66-6.4) & 1.44(0.71-2.94) \\ & & & \\ 29(14.3) & 186(25.4) & 1 & 1 \\ 78(38.4) & 353(48.2) & 1.42(0.89-2.25) & 0.76(0.43-1.33) \\ 75(36.9) & 177(24.1) & 2.72(1.69-4.37) & 1.58(0.88-2.82) \\ 21(10.3) & 17(2.3) & 7.92(3.74-16.77) & 4.48(1.73-11.58)\end{array}$

\section{Patient}

Age
$<70$ years
$70-79$ years
$\geq 80$ years
Sex (female)
Residency
Home
Care/nursing home
Hospital
Hospice
Main diagnosis
Cancer
Heart failure/CVA
MS/ALS
COPD
Accumulation of age-related health problems/dementia/psychiatric disorder
Other
Besides main diagnosis also ${ }^{\text {a }}$
Physical illness
Psychiatric disorder
Accumulation of age-related health problems
Dementia
Psychosocial or existential problems
(1)

$\begin{array}{llll}78(39) & 260(35.6) & 1 & 1 \\ 36(18) & 240(32.9) & 0.5(0.33-0.77) & 0.38(0.21-0.68) \\ 86(43) & 230(31.5) & 1.25(0.88-1.78) & 0.53(0.31-0.93) \\ 104(51.7) & 339(46.2) & 1.25(0.91-1.71) & 9 \\ 136(67.7) & 615(84) & 1 & \\ 33(16.4) & 57(7.8) & 2.62(1.64-4.18) & 1.31(0.7-2.47) \\ 17(8.5) & 20(2.7) & 3.84(1.96-7.53) & 3.01(1.15-7.85) \\ 15(7.5) & 40(5.5) & 1.7(0.91-3.16) & 2.01(0.9-4.49) \\ & & & \\ 73(36.1) & 551(75.1) & 1 & 1 \\ 23(11.4) & 35(4.8) & 4.96(2.78-8.86) & 4.43(2.08-9.42) \\ 7(3.5) & 22(3) & 2.4(0.99-5.82) & 0.85(0.25-2.87) \\ 7(3.5) & 33(4.5) & 1.6(0.68-3.75) & 0.7(0.2-2.46) \\ 64(31.7) & 40(5.4) & 12.08(7.59-19.21) & 6.94(3.58-13.46) \\ 28(13.9) & 53(7.2) & 3.99(2.37-6.7) & 3.42(1.77-6.6) \\ & & & \\ 94(50.5) & 299(49.9) & 1.03(0.74-1.43) & \mathbb{9} \\ 29(15.6) & 53(8.8) & 5.17(2.28-11.71) & 3.91(1.41-10.83) \\ 29(15.6) & 53(8.8) & 1.9(1.17-3.1) & 1.58(0.77-3.24) \\ 6(3.2) & 9(1.5) & 2.19(0.77-6.22) & \mathbb{9} \\ 34(18.3) & 31(5.2) & 4.1(2.44-6.88) & 2.25(1.13-4.5)\end{array}$


Table 4 Characteristics associated with difficult consultations as perceived by SCEN physicians, 2016-2017 (Continued)

\begin{tabular}{|c|c|c|c|c|}
\hline & $\begin{array}{l}\text { Difficult } \\
(N=203)\end{array}$ & $\begin{array}{l}\text { Not difficult } \\
(N=735)\end{array}$ & $\begin{array}{l}\text { Univariable } \\
\text { Odds ratio } \\
\text { (95\% Cl) }\end{array}$ & $\begin{array}{l}\text { Multivariable } \\
\text { Odds ratio } \\
\text { (95\% Cl) }\end{array}$ \\
\hline & N (\%) & N (\%) & & \\
\hline \multicolumn{5}{|l|}{ Reasons to request EAS } \\
\hline Loss of dignity & $90(44.3)$ & $364(49.6)$ & $0.81(0.59-1.11)$ & 9 \\
\hline Overall weakness & $86(42.4)$ & $457(62.3)$ & $0.45(0.33-0.61)$ & $0.78(0.51-1.2)$ \\
\hline Being tired with life & $17(8.4)$ & $20(2.7)$ & $3.26(1.68-6.35)$ & $0.95(0.37-2.43)$ \\
\hline Pointless suffering & $45(22.2)$ & $156(21.3)$ & $1.06(0.73-1.54)$ & १ \\
\hline Knowing that suffering will not get better & $93(45.8)$ & $382(52)$ & $0.78(0.57-1.06)$ & 9 \\
\hline Fear of suffocation & $15(7.4)$ & $89(12.1)$ & $0.58(0.33-1.02)$ & $0.73(0.32-1.67)$ \\
\hline Invalidity & $42(20.7)$ & $115(15.7)$ & $1.4(0.95-2.08)$ & 9 \\
\hline Depression $^{\mathrm{b}}$ & $12(5.9)$ & $1(0.1)$ & - & - \\
\hline Dependency & $92(45.3)$ & $353(48.1)$ & $0.9(0.66-1.22)$ & 9 \\
\hline Not wanting to be a burden for family & $22(10.8)$ & $32(4.4)$ & $2.67(1.51-4.7)$ & $1.32(0.58-2.99)$ \\
\hline Physical suffering ${ }^{c}$ & $72(35.5)$ & 405 (55.2) & $0.45(0.32-0.62)$ & $0.62(0.4-0.96)$ \\
\hline
\end{tabular}

$\mathrm{N}$ number, $\mathrm{Cl}$ confidence interval; 9 , not significant in univariable analysis, thus not included in multivariable analysis; ${ }^{\mathrm{a}} \mathrm{Missing}$ values $=153 ;{ }^{\mathrm{b}} \mathrm{Not}$ included in analysis due to small sample size; 'Includes pain, vomiting and dyspnea; Missing values ranging from 1 to 35

concerning patients with accumulation of age-related health problems, dementia or a psychiatric disorder as main diagnosis had higher odds of characteristics of patients that contribute to a consultation being perceived difficult $(\mathrm{OR}=2.91)$, compared to patients with cancer. The presence of a psychiatric disorder $(\mathrm{OR}=8.24)$ or psychosocial or existential problems $(\mathrm{OR}=2.24)$ besides the main diagnosis had higher odds of characteristics of patients that contribute to a consultation being perceived difficult.

\section{Discussion}

We found that one out of five EAS consultations is perceived difficult by SCEN physicians. Perceived complexities are mostly related to the patient characteristics and the assessment of due care criteria. Characteristics that are associated with a higher likelihood of difficult consultations are the certainty of the attending physician on whether or not to perform the EAS before the consultation with the SCEN physician (not already promised to grant the request), patient's residence (not home), main diagnosis of the patient (not cancer), and the presence of a psychiatric disorder or psychosocial or existential problems besides the main diagnosis. Characteristics that are associated with a lower likelihood of difficult consultation are high patient's age and physical suffering as important reason to request EAS.

\section{Frequency of consultations that are perceived difficult}

Over one out of five consultations is perceived difficult by SCEN physicians. If we multiply with all consultations in 2016 [10], approximately 1750 of all consultations that were performed by SCEN physicians in 2016 are possibly perceived difficult. 1750 is substantial and it would be good if this would be subject of discussion in intervision. This difficulty is not necessarily problematic. EAS is an inherently sensitive subject that needs careful consideration. With regard to SCEN physicians performing their work in the review process, it is especially important that they are able to assess the due care criteria. The fact that SCEN physicians perceive difficulties does not necessarily mean that there are problems with the assessment of due care criteria. SCEN physicians received training in assessing the due care criteria and thus have the most experience to deal with complexities.

\section{Characteristics associated with difficult consultations}

In recent years, the public debate mainly focuses on patients with dementia, psychiatric disorder, or accumulation of age-related health problems, as difficult cases [6-8]. Our findings confirm that these cases are often perceived difficult by SCEN physicians, as we found a strong association between these diagnoses and perceived difficulty, and as they were mentioned by SCEN physicians as complexities. This is in agreement with results obtained by Bolt et al. (2015) in a study among attending physicians [7]. One explanation for these cases being perceived difficult can be related to the difficulty of assessing whether suffering is unbearable in these patient groups, where psychosocial suffering is mainly present. Besides, from previous research we know that physicians are less likely to judge suffering unbearable in psychosocial suffering, present in for example early stage dementia, compared to physical suffering $[7,11]$. Other explanations may be the uncertainty about the availability of alternative treatment options in patients with psychiatric disorders and about whether the request was voluntary and well-considered in patients with dementia [7, 12]. 
Table 5 Characteristics associated with consultations perceived as difficult by SCEN physicians for the assessment of due care criteria and patient characteristics, 2016-2017

\begin{tabular}{lll}
\hline & \multicolumn{2}{l}{ Multivariable odds ratio $(95 \% \mathrm{Cl})$} \\
\cline { 2 - 3 } & The assessment of due care criteria & Patient characteristics \\
\hline Difficult (score $\geq 4)$ & $139(14.8)^{\mathrm{a}}$ & $97(10.3)^{\mathrm{a}}$
\end{tabular}

\section{SCEN physician}

Number of consultations per year

$$
\begin{aligned}
& <5 \\
& 5-9 \\
& 10-14 \\
& \geq 15
\end{aligned}
$$

\section{Attending physician}

Profession

General practitioner

Medical specialist

1

Elderly care physician

$0.93(0.32-2.73)$

1

Works at End of life clinic

$0.62(0.24-1.61)$

$3.02(1.09-8.35)$

$1.82(0.85-3.89)$

$0.99(0.37-2.68)$

Certainty of decision before consultation

Already promised to grant the request

1

Decided to grant the request

Probably wants to grant the request

$0.72(0.36-1.44)$

$0.64(0.25-1.63)$

Doubts about/doesn't want to grant the request

$1.93(0.97-3.83)$

$0.74(0.35-1.55)$

$1.27(0.6-2.7)$

$4.69(1.71-12.88)$

$3.52(1.22-10.18)$

\section{Patient}

Age

$<70$ years

1

70-79 years

$0.37(0.18-0.75)$

$0.41(0.21-0.79)$

$\geq 80$ years

9

$$
\text { Sex (female) }
$$

Home

Care/nursing home

Hospital

Hospice

1

$1.52(0.76-3.05)$

$1.45(0.48-4.41)$

$2(0.76-5.24)$

1

$3.54(1.44-8.66)$

$0.79(0.16-3.89)$

$1.18(0.29-4.75)$

$13.52(6.4-28.56)$

$5.05(2.42-10.53)$

9

9

$1.96(0.87-4.46)$

9

$2.25(1.07-4.71)$
1

$0.41(0.18-0.92)$

$1(0.52-1.89)$

१

1

$1.72(0.8-3.69)$

5.08 (1.8-14.31)

$3.27(1.32-8.1)$

1

$2.17(0.87-5.39)$

$0.94(0.2-4.45)$

$0.66(0.15-2.89)$

$2.91(1.31-6.43)$

$1.35(0.56-3.27)$

9

$8.24(3.11-21.86)$

9

9

$2.24(1.07-4.72)$

Psychosocial or existential problems 
Table 5 Characteristics associated with consultations perceived as difficult by SCEN physicians for the assessment of due care criteria and patient characteristics, 2016-2017 (Continued)

\begin{tabular}{lll}
\hline & Multivariable odds ratio $(95 \%$ Cl) \\
\cline { 2 - 3 } & The assessment of due care criteria & Patient characteristics \\
\hline Reasons to request EAS & $\mathbf{9}$ & $\mathbf{9}$ \\
Loss of dignity & $0.93(0.57-1.54)$ & $1.22(0.69-2.17)$ \\
Overall weakness & $0.94(0.34-2.57)$ & $1.47(0.52-4.18)$ \\
Being tired with life & $\mathbf{9}$ & $\mathbf{9}$ \\
Pointless suffering & $\mathbf{9}$ & $\mathbf{9}$ \\
Knowing that suffering will not get better & $0.62(0.21-1.8)$ & $\mathbf{9}$ \\
Fear of suffocation & $\mathbf{9}$ & $\mathbf{9}$ \\
Invalidity & - & - \\
Depression & $\mathbf{9}$ & $\mathbf{9}$ \\
Dependency & $1.67(0.7-4)$ & $1.3(0.49-3.5)$ \\
Not wanting to be a burden for family & $0.69(0.41-1.15)$ & $0.87(0.49-1.52)$ \\
Physical suffering &
\end{tabular}

$\mathrm{N}$ number, $\mathrm{Cl}$ confidence interval; $\mathfrak{9}$, not significant in univariable analysis, thus not included in multivariable analysis; ${ }^{\mathrm{a}} \mathrm{Number}$ (percentage); ${ }^{\mathrm{b}}$ Missing values = 153; ' Includes pain, vomiting and dyspnea; Missing values ranging from 1 to 35

These explanations were also mentioned separately as complexities by SCEN physicians (Table 3).

Also, consultations concerning patients with a psychiatric disorder besides their main diagnosis are perceived difficult more than patients without a psychiatric disorder. Yet, SCEN physicians do not find it more difficult to judge the due care criteria for this specific patient group, but do perceive more difficulty in contact with the patient. An explanation may be that with the assessment of the due care criteria the main diagnosis suffices, and thus the psychiatric disorder on top of that does not necessarily complicate this assessment.

Not only the 'complex' cases present in the public debate, patients with dementia, psychiatric disorder, or accumulation of age-related health problems, are perceived as difficult. Patients with the diagnosis heart failure or CVA are more often perceived difficult by SCEN physicians compared to cancer patients. The unpredictable course of the heart failure or CVA disease trajectory, compared to predictability of cancer trajectory, might account for some of the difficulty in characterizing the process of dying [13-15]. This unpredictability may complicate the assessment of the criterion unbearable suffering without prospect of relief. Also, consultations concerning patients with other diagnoses (e.g. Parkinson's disease, lung fibrosis) are perceived difficult more often than cancer patients. Explanations may be that these concern diagnoses that SCEN physicians have not seen a lot or are not familiar with, and are therefore harder to assess, which is also mentioned by SCEN physicians (Table 3). Another explanation may be that these other diagnoses are in themselves difficult.
Not only the patient's diagnosis is associated with perceived difficulty of consultations. First, if the patient has a high age ( $\geq 70$ years), the likelihood of difficult consultations as perceived by SCEN physicians is lower, compared to patients with a lower age $(<70$ years). Older people have a reduced life expectancy compared to younger people and therefore an EAS request from younger people could be more confronting for SCEN physicians. Second, patients staying in the hospital have a higher likelihood of difficult consultations than patients staying at home. SCEN physicians experience difficulties with the patient, and not in assessing the due care criteria. Hospitalization at the end of life often takes place because of an acute medical situation [16], and this may cause difficulties in interaction with the patient, such as stress. Third, the uncertainty of the attending physician to grant the request is associated with perceived difficulty for the SCEN physician and was mentioned by SCEN physicians as complexity in more than one way. This may be explained by difficulties that arise from different opinions of the attending physician and SCEN physician or uncertainty about this decision because the EAS request or the situation in itself is complex.

\section{Strengths and limitations}

A major strength of this study is the high number of cases and response rate. Another strength is the inclusion of both an open-ended question on descriptions of perceived complexities during the most difficult consultation, and analyses to assess which characteristics are associated with difficult consultations. Both the 
description of perceived complexities as the analyses of characteristics associated with difficult consultations have similar results which adds to the reliability of conclusions made in this study. A limitation is the small numbers of patients with some specific characteristics which resulted in wide confidence intervals. Therefore, these results should be interpreted with caution. Recall bias could be another limitation and results in SCEN physicians not remembering the request well. On the other hand, complex cases are probably remembered better than not complex cases. Another limitation is the small amount of characteristics of SCEN physicians in analyses. Further research should take these into account.

\section{Conclusions}

Complexities perceived by SCEN physicians in EAS consultations are not limited to the 'complex' cases present in the current public debate about EAS, e.g. patients with psychiatric disorders, dementia, and tired of living. Difficult consultations perceived by SCEN physicians are not rare, as they occur in one out of five consultations. This difficulty is not necessarily problematic, as EAS is a sensitive subject. Yet, attention in the SCEN program is needed for these complex consultations. Training and intervision is already implemented in the SCEN program. Attention for these complexities in intervision could indicate if there is a need among SCEN physicians to enhance knowledge and skills in training and to receive specific support in intervision on these complexities.

\section{Abbreviations}

Cl: Confidence interval; EAS: Euthanasia and physician-assisted suicide; OR: Odds ratio; RDMA: Royal dutch medical association

\section{Acknowledgements}

Not applicable.

\section{Ethical approval and consent to participate}

This study did not require review by an ethics committee under the Dutch Medical Research Involving Human Subjects Act, since it did not involve imposing any interventions or actions and no patients were involved. Informed consent was assumed on return of the survey.

\begin{abstract}
Authors' contributions
BDOP designed the study. TDB performed data management, statistical analysis, and interpreted the data. BDOP and HRWP coded the open-ended questions. TDB prepared the initial draft of this manuscript. HRWP and BDOP critically revised the manuscript for intellectual content and commented on subsequent drafts of the manuscript. TDB, HRWP and BDOP contributed to the final draft of the manuscript and gave final approval for submission.
\end{abstract}

\section{Funding}

No funding.

\section{Availability of data and materials}

The datasets used and/or analysed during the current study are available from the corresponding author on reasonable request.

\section{Consent for publication}

Not applicable.

\section{Competing interests}

The authors declare that they have no competing interests.

Received: 23 July 2019 Accepted: 29 November 2019

Published online: 09 January 2020

\section{References}

1. Onwuteaka Philipsen BD, Legemaate J, van der Heide A, van Delden $H$, Evenblij K, El Hammoed I, Pasman HR, Ploem C, Pronk R, van de Vathorst S, et al. Derde evaluatie Wet toetsing levensbeëindiging op verzoek en hulp bij zelfdoding. In. ZonMw: Den Haag; 2017.

2. de Haan J. The new Dutch law on euthanasia. Med Law Rev. 2002;10(1):5775.

3. Jansen-van der Weide MC, Onwuteaka-Philipsen BD, van der Wal G. Quality of consultation and the project 'Support and Consultation on Euthanasia in the Netherlands' (SCEN). Health Policy. 2007:80(1):97-106.

4. Jansen-van der Weide MC, Onwuteaka-Philipsen BD, van der Wal G. Implementation of the project 'Support and Consultation on Euthanasia in The Netherlands' (SCEN). Health Policy. 2004;69(3):365-73.

5. Onwuteaka-Philipsen B, Buiting H, Rurup M, Pasman HR, Willems D. Evaluatie van SCEN: Wat is goede steun en consultatie? In. Amsterdam: EMGO+; 2010

6. Snijdewind MC, van Tol DG, Onwuteaka-Philipsen BD, Willems DL Complexities in euthanasia or physician-assisted suicide as perceived by Dutch physicians and patients' relatives. J Pain Symptom Manag. 2014;48(6): 1125-34.

7. Bolt EE, Snijdewind MC, Willems DL, van der Heide A, Onwuteaka-Philipsen BD. Can physicians conceive of performing euthanasia in case of psychiatric disease, dementia or being tired of living? J Med Ethics. 2015;41(8):592-8.

8. Ypma TD, Hoekstra HL. Beoordeling van euthanasieverzoek door SCENartsen. Ned Tijdschr Geneeskd. 2015;159(10).

9. Brinkman-Stoppelenburg A, Vergouwe $Y$, van der Heide A, OnwuteakaPhilipsen BD. Obligatory consultation of an independent physician on euthanasia requests in the Netherlands: what influences the SCEN physicians judgment of the legal requirements of due care? Health Policy. 2014:115(1):75-81.

10. KNMG. Spiegelinformatie SCEN 2016. In. KNMG: Utrecht; 2017.

11. Kouwenhoven PS, Raijmakers NJ, van Delden JJ, Rietjens JA, van Tol DG, van de Vathorst S, de Graeff N, Weyers HA, van der Heide A, van Thiel GJ. Opinions about euthanasia and advanced dementia: a qualitative study among Dutch physicians and members of the general public. BMC Med Ethics. 2015;16:7.

12. Evenblij K, Pasman HRW, Pronk R, Onwuteaka-Philipsen BD. Euthanasia and physician-assisted suicide in patients suffering from psychiatric disorders: a cross-sectional study exploring the experiences of Dutch psychiatrists. BMC Psychiatry. 2019;19(1):74.

13. Mcllvennan CK, Allen LA. Palliative care in patients with heart failure. BMJ : Br Med J. 2016;353.

14. Murray SA, Kendall M, Boyd K, Sheikh A. Illness trajectories and palliative care. BMJ (Clin Res ed). 2005;330(7498):1007-11.

15. Levenson JW, McCarthy EP, Lynn J, Davis RB, Phillips RS. The last six months of life for patients with congestive heart failure. J Am Geriatr Soc. 2000; 48(S1):S101-9

16. De Korte-Verhoef MC, Pasman HRW, Schweitzer BPM, Francke AL, Onwuteaka-Philipsen BD, Deliens L. Reasons for hospitalisation at the end of life: differences between cancer and non-cancer patients. Support Care Cancer. 2014;22(3):645-52.

\section{Publisher's Note}

Springer Nature remains neutral with regard to jurisdictional claims in published maps and institutional affiliations. 